\title{
AVALIAÇÃO DA SEXUALIDADE EM MULHERES COM SANGRAMENTO UTERINO ANORMAL
}

\author{
Bianca E. B. Franceschina*, Prof. Dra. Ilza Maria Urbano Monteiro, Elaine Garcia, Maria Margarete Hidalgo, Sara \\ Castro, Ximena Espejo-Arce
}

\begin{abstract}
Resumo
O sangramento uterino anormal (SUA), ou menorragia, é definido como qualquer perda anormal de sangue de origem uterina, descartando afecções orgânicas demonstráveis do trato genital e gravidez. Como distúrbio frequente em qualquer época do período reprodutivo feminino, é importante analisar a influência do SUA na sexualidade das mulheres com esta queixa.
\end{abstract}

Palavras-chave: Sangramento uterino anormal, sexualidade, qualidade de vida.

\section{Introdução}

O Sangramento Uterino Anormal (SUA) ou menorragia é definido como toda perda sanguínea anormal de origem uterina, na ausência de afecção orgânica demonstrável do trato genital e da gestação. O sangramento uterino anormal é uma afecção frequente que pode afetar negativamente aspectos físicos, emocionais, sexuais e profissionais, piorando a qualidade de vida das mulheres. As capacidades funcional, emocional e social de mulheres com SUA são semelhantes à de pessoas cronicamente doentes, uma vez que podem levar à restrição das atividades profissional, social, familiar e sexual, além da preocupação de que o sangramento intenso indique outros problemas de saúde. A sexualidade feminina sofre mais influência de fatores psicológicos e sociais que a masculina.(1). Tendo em vista a interferência negativa na QV das mulheres com queixa de SUA e ausência na literatura de estudo que avalie a influência do SUA na sexualidade, é importante avaliar se há relação entre SUA e sexualidade para melhorar a QV das mulheres com esta queixa.

Este trabalho tem por objetivo avaliar a influência do SUA sobre a função sexual, sobre a frequência semanal de relações sexuais e sobre a qualidade de vida das mulheres de acordo com os escores do Female Sexual Function Index (FSFI) e o World Health Organization Quality of Life Questionnaire abbreviated version (WHOQOL-BREF), auto-respondidos por mulheres entre 18 e 49 com SUA aguardando consulta agendada no Cemicamp.

Foram excluídas mulheres que não tinham parceria sexual e mulheres cujo parceiro tinha ejaculação precoce e/ou disfunção erétil.

\section{Resultados e Discussão}

Mulheres entre 18 e 49 anos de idade com diagnóstico de SUA aguardando sua consulta agendada no Cemicamp, foram convidadas a participar do estudo completando os questionários auto-respondidos Female Sexual Function Index (FSFI) e o World Health Organization Quality of Life Questionnaire abbreviated version (WHOQOL-BREF). Foram selecionadas mulheres de 18 a 49 anos com diagnóstico de SUA, com vida sexual ativa, cujos parceiros não tivessem ejaculação precoce e/ou disfunção erétil, e sem histórico de abuso sexual.

A avaliação da qualidade de vida foi feita por meio do escore do questionário WHOQOL-BREF e a avaliação da sexualidade por meio da análise do questionário FSFI. Os dados das pacientes foram inseridos em um banco de dados dedicado ao estudo.

No período de setembro/2018 até junho/2019 foram convidadas a participar do estudo 140 pacientes, das quais
101 responderam os questionários. Foram excluídas do estudo 22 pacientes de acordo com os critérios previamente apresentados.

Utilizamos o FSFI com ponto de corte total ou menor que 35,5 e maior que 35,5 respectivamente com risco maior e menor para disfunção, sem considerar separadamente as variáveis dor, excitação, lubrificação, orgasmo, desejo e satisfação. Como resultado, dentre as 79 mulheres incluídas no estudo $27,84 \%$ apresentaram maior risco para disfunção sexual.

Quanto à qualidade de vida, ao avaliar apenas a percepção de QV, 56,96\% tem uma percepção boa ou muito boa da sua QV.

\section{Conclusões}

É notável que um alto número de mulheres com SUA tem maior risco para disfunção sexual (aproximadamente um terço das paciente incluídas), entretanto deve-se avaliar as variáveis específicas para aprofundar em que domínio há maior influência do SUA.

O FSFI é o primeiro instrumento para avaliação da função sexual feminina validado em português e que cumpre todos os requisitos propostos para o protocolo de validação internacional, mas é importante a padronização e validação de instrumentos de avaliação que não consideram a resposta sexual feminina imagem espelho da masculina como proposto por Basson et al (2000).

Ao avaliar os escores do WHOQOL-BREF, nota-se que, apesar da percepção da qualidade de vida das participantes ser boa ou muito boa, os domínios específicos quando avaliados podem mostrar divergências e, portanto devem ser avaliados separadamente.

Devido à grande importância e baixa quantidade de estudos na literatura avaliando a influência do SUA na sexualidade, daremos continuidade ao estudo com o aperfeiçoamento da convocação de participantes e realizaremos uma avaliação estatística mais aprofundada e correlacionaremos os resultados obtidos nos diferentes questionários.

\section{Agradecimentos}

Agradeço ao CNPQ pela concessão da bolsa de iniciação científica e à minha orientadora e co-autoras neste projeto por toda ajuda.

1. Moore AA. Heavy menstrual bleeding. Adv.NPS. PAS.2013;4(1):21-23. 3 